Article

\title{
Fuzzy Similarity Used by Micro-Enterprises in Marketing Communication for Sustainable Development
}

\author{
David Schüller ${ }^{1}$ and Karel Doubravský ${ }^{2, *}$ \\ 1 Department of Management, Faculty of Business and Management, Brno University of Technology, Kolejni \\ 2906/4, 61200 Brno, Czech Republic; schuller@fbm.vutbr.cz \\ 2 Department of Informatics, Faculty of Business and Management, Brno University of Technology, Kolejni \\ 2906/4, 61200 Brno, Czech Republic \\ * Correspondence: doubravsky@fbm.vutbr.cz; Tel.: +420-54114-3723
}

Received: 4 July 2019; Accepted: 18 September 2019; Published: 30 September 2019

check for updates

\begin{abstract}
The purpose of this paper is to present fuzzy reasoning as a formal tool for determining the differences in perception of individual communication channels by customers. These differences in customer perception are important for micro-enterprises to develop an effective green advertising campaign. These kinds of enterprises are not able to conduct their own extensive marketing research or use the service of marketing agencies. Micro-enterprises are the cornerstone for sustainable local economic growth where the community plays an irreplaceable role for sustainable development. Marketing communication is unique and complex because it focuses on feelings, moods, and personal preferences. The main problem is the uncertainty of this input data which makes it difficult to develop effective green advertising campaigns. Fuzzy sets and fuzzy reasoning are used to make verbal descriptions suitable for computer applications. A fuzzy pairwise similarity is used in this paper. The case study has eight relevant variables/marketing communication media, e.g., e-mailing, social networks, web pages, text messaging, newspapers, phone calls, posters and radio, and five segments of respondents selected by age. Each segment is presented as a fuzzy conditional statement. A set of fuzzy pairwise similarities is generated.
\end{abstract}

Keywords: micro-enterprises; marketing communication; green advertising; sustainable development; verbal description; fuzzy similarity

\section{Introduction}

Sustainability is a crucial topic confronting a wide range of businesses, prompting marketers and academics to set novel and relevant targets [1]. Methods for developing sustainable processes, products, and services became a key topic challenge for marketing professionals and other entities like governments. Sustainable marketing is based on the theory of sustainability and covers the same three dimensions-environmental, economic, and social. Sustainable marketing focuses on the future of mutual relationship and communication between enterprises and their customers [2,3]. Even though both customers and enterprises realize the importance of sustainability, it is difficult for enterprises to draw customers' attention via sustainable marketing strategies [4]. Enterprises need to communicate their sustainable marketing strategies effectively and marketing communication has its irreplaceable role in sustainable development. Marketing communication has the potential to clearly communicate new sustainable kinds of business to consumers [5,6].

Marketing communication is associated with green advertising. Banerjee et al. [7] defines the green advertising in these three aspects: 
1. Any advert that includes the relationship between a product and biophysical environment;

2. Any advert that comprises a green lifestyle with or without highlighting a product;

3. Any advert that promotes a corporate image of environmental responsibility.

One of the most well-known definitions of green advertising is based on a two-tier approach. The first tier comprises and signifies the technical perspective attitude and the second tier highlights the wider concepts of sustainability [8]. This definition points out the interconnection between technical aspects of advertising and sustainability. Therefore, it is crucial for the purposes of the article and presented case study. Many other authors focus on the concept of green advertising at different levels [9-11]. McDonald and Oates [11] argue that green consumers try to apply their sustainable values into purchasing criteria such as energy efficiency of local sourcing. The authors also emphasize that it is easier to encourage sustainable buying behavior in fast-moving goods like food than in occasional purchase of large products such as a fridge or motorcar. These authors add in their later research that demographics and green behavior of consumers are often taken into consideration so that relevant target groups of consumers could be identified with more effectiveness [12].

A micro-enterprise used in the case study is related to the McDonalds' and Oates' research mainly in these aspects-food industry and local sourcing. The segments of consumers are analyzed from the perspective of demographic segmentation (age) in the field of marketing communication.

Micro-enterprises are defined as firms with fewer than five employees [13]. According to the U.S. Small Business Administration, micro-enterprise is defined as an enterprise that has fewer than five employees [14]. On the contrary, The World Bank defines micro-enterprise as a company that has up to 10 employees and its total assets of up to $\$ 10,000$ and total annual sales of up to $\$ 100,000$ [15]. The European Union definition of micro-enterprises is relevant for the purposes of this paper. The European Commission defines a micro-enterprise that has up to 10 employees, a balance sheet total below EUR two million, and turnover also below EUR two million [16].

It is important to see these entities not only from the perspective of sustainable economic growth but also their social, environmental, and cultural dimensions. Micro-enterprises are community based, which is crucial supposition to bring together all elements of sustainable development. Micro-enterprises foster sustainable development only if they are also integrated into community development [17].

Sustainable entrepreneurship brings a significant change in business targets [18]. It is essential to shift from profit-centered aims to sustainable-centered ones, see [19]. The interaction between micro-enterprises and customers plays a key role to reach the sustainable-centered targets and both subjects have to be well-motivated to support sustainable entrepreneurship. Solid intent is needed to become a sustainable entrepreneur who can support the whole community. This intent is an important stimulant for becoming sustainable entrepreneur [20].

Micro-enterprises are closely involved in communities and they have a better chance of being recognized when they provide products or services. It is beneficial for micro-enterprises to focus on green processes as they can easily attract potential customers. Entrepreneurs providing services ought to acquire a distinct market, based on green activities [21].

It is necessary for companies to inform the potential customer about the sustainable intentions, to raise awareness, and try to influence consumer behavior towards sustainable development [18].

For these purposes, entrepreneurs have to strive to use effective marketing communication and an optimal communication mix.

Nowadays marketers face a wide choice of media channels in communication with their customers. It is necessary to manage marketing communications carefully and effectively. Apart from traditional marketing channels, online media is increasingly significant in the communication mix. Online marketing communication contains various kinds of media such as social media, search engine marketing, email marketing, display advertising, or mobile advertising. The internet has become an everyday part of the lives of millions of people around the world [22]. 
Today, marketing communication includes creating and maintaining online communities. Interaction and collaboration with customers allows enterprises to get a better understanding of their wishes and needs [23].

Good coordination of various communication channels is the key in integrated marketing communication. Enterprises can deliver the message to the customer with a higher impact by using more communication channels. This impact is a result of the fact that a customer receives a consistent message from more marketing channels, see [24], which is more effective than using only one communication medium.

Enterprises have to get to know how customers perceive the importance of individual communication channels to provide a consistent message with a high synergy effect. Several studies focused on synergy in traditional marketing channels [25], but also between traditional and online media $[26,27]$.

Real-world modeling and optimization of marketing communications (MC) is based on uncertain inputs, such as the personal knowledge. This uncertainty of the input information often excludes statistical methods, see $[28,29]$. The normality and the minimum number of data sets are the essential requirements for the correct applications of statistical methods; for details see, e.g., [30,31].

Realistic MC problems are unique and usually difficult to measure and quantify. This uniqueness may make it impossible to isolate them without significantly distorting the input information which has a significant impact on the accuracy of the problem. This is the main reason for being unable to use statistical methods for real MC-related tasks.

The objective way to evaluate the probability of an event is to repeat the measurement/observation of the outcome of the event many times under the same conditions. This is practically impossible. This is the main reason why new formal tools are necessary for the study of marketing communication tasks when the model must be neither too simplified nor too specific. This paper presents a new approach how to use fuzzy logic to integrate shallow MC knowledge items into a formal model using small data sets and to obtain a relationship between the monitored variables.

MC indicators have been produced for various purposes by a wide spectrum of institutions leading to diverse indicators. However, using an adequate and consistent set of indicators to measure marketing communication for a company or customer is not easy. There are two approaches for solving MC realistic problems:

- Common sense approach based on feelings, experiences, analogies;

- Formal approach based on mathematical models.

Fuzzy sets are tools that allow to integrate both of the above approaches.

The article contains the following sections: Materials and Methods, Case Study, Discussion and Conclusion. The mathematical framework of fuzzy reasoning is explained in the section Materials and Methods. The authors deliberately chose a confectionery micro-business for the case study because customers in this sector are more sensitive to sustainable buying behavior [11]. The owner of the chosen micro-enterprise tries to lead the company with the principles of sustainable development, mainly by using local bio-raw materials, using paper packaging instead of plastic. The owner plans to organize baking courses for customers as a new activity of her micro-enterprise which produces confectionary products. Within these courses, she intends to promote the idea of the ecology of sustainability, especially in the area of using local resources, eco-friendly packaging, and to eliminate semi-finished products. Baking courses also have a social overlap as they are also targeted at the local community, which will have a positive impact on strengthening local people's relationships. On the basis of these facts the following research question is formulated.

What are the differences in perception of communication channels by customers based on their age? Fuzzy reasoning will be used for this purpose. 


\section{Materials and Methods}

\subsection{Fuzzy Reasoning}

A fuzzy set theory is based on the premise that the key elements of human thinking are not numbers but words, see, e.g., [32-34].

In the case of large amounts of input data, the key feature of human thinking is the extraction of only experiences that is relevant to the problem, see, e.g., [35-37]. Fuzzy reasoning is based on a very similar principle.

There are many different fuzzy thinking algorithms with different levels of sophistication, see, e.g., [38,39]. However, many of these algorithms are too complex and difficult to understand to widely use. MC experts will be willing to accept fuzzy reasoning algorithms only if these algorithms are not disproportionately theoretically demanding. Therefore, the following presentation of fuzzy reasoning is based on an easy to understand algorithm, for details see $[33,40,41]$.

A verbal value is a "value" that is given by words, e.g., very low, low, medium, high, around 5 degrees Celsius, etc. A verbal value of a monitored variable is transformed into a fuzzy set by the specification of a grade of membership. For example, a verbal value around 5 degrees Celsius of the variable temp is transformed into a fuzzy using the membership function $\mu$, see Figure 1 . The membership function expresses whether a value belongs to a fuzzy set; for details see [42,43]. A typical fuzzy set $5 c$ of the verbal value around 5 degrees Celsius of the variable temp is

$$
b<\text { temp }<c
$$

where (see Figure 1)

$$
\mu_{5 C}(\text { temp }) ; \text { temp } \in[0, \infty]
$$

is the grade of membership of the numerical value of the variable temperature to the fuzzy set $5 c$. There are two fuzzy intervals, namely, see Figure 1:

$$
a<\text { temp }<b, c<\text { temp }<d
$$

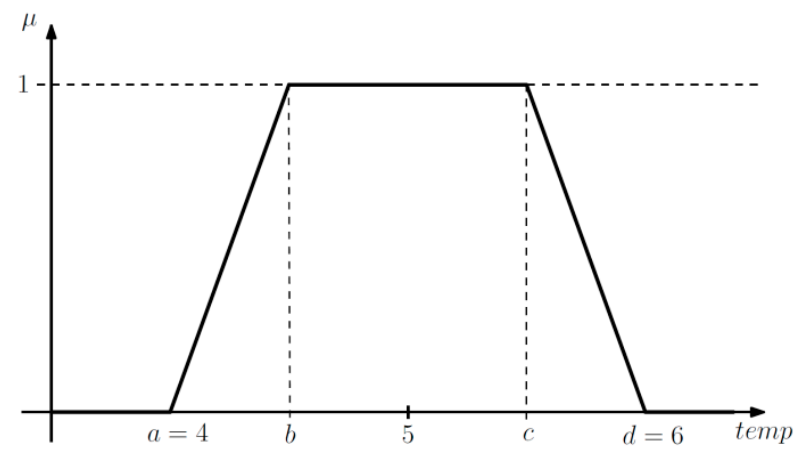

Figure 1. The membership function.

There are two intervals of numerical values of the variable temp which belong to the fuzzy set $5 c$ with the zero grade of membership:

$$
[0, a],[d, \infty]
$$


A basic fuzzy model is a set of $m n$-dimensional conditional statements; see, e.g., [33,44]:

$$
\begin{aligned}
& \text { if } A_{1,1} \text { and } A_{1,2} \text { and } \ldots \text { and } A_{1, n} \text { then } B_{1} \text { or } \\
& \text { if } A_{2,1} \text { and } A_{2,2} \text { and } \ldots \text { and } A_{2, n} \text { then } B_{2} \text { or } \\
& \text {. } \\
& \text {. } \\
& \text { if } A_{m, 1} \text { and } A_{m, 2} \text { and } \ldots \text { and } A_{m, n} \text { then } B_{m} \text {, }
\end{aligned}
$$

where fuzzy sets:

$$
A_{i, j}, B_{i} \text { for } i=1,2, \ldots, m \text { and } j=1,2, \ldots, n
$$

are one-dimensional fuzzy sets and can be easily specified or/and modified using points $a, b, c, d$ of a variable $X_{j}$ (see Figure 1).

The model (5) represents a function

$$
B_{i}=f_{i}\left(A_{j}\right),
$$

where $A_{j}$ is the $j$-th independent variable and $B_{i}$ is the dependent variable. However, a dependent variable $B_{i}$ is not considered in this problem and paper:

$$
0=f_{i}\left(A_{j}\right)
$$

Therefore, the model (5) is replaced by the following matrix $(m \times n)$ :

$$
\begin{aligned}
A_{1,1} & \ldots A_{1, n} \\
A_{2,1} & \ldots A_{2, n} \\
\cdot & \\
\cdot & \\
A_{m, 1} & \ldots A_{m, n}
\end{aligned}
$$

\subsection{Fuzzy Similarity and Similarity Graphs}

A similarity s of two $n$-dimensional fuzzy sets $V, W$ is:

$$
s(n, V, W)=\min \left(\max \left(\min \left(\mu_{V}\left(x_{j}\right), \mu_{W}\left(x_{j}\right)\right)\right)\right),
$$

where $j=1,2, \ldots, n$ and $x_{j}$ is a concrete value of a monitored variable $X_{j}$.

The similarity $s \in[0 ; 1], s=0$ means there is no similarity of the fuzzy sets $V$ a $W, s=1$ means there is $100 \%$ similarity, i.e., the fuzzy sets $V$ and $W$ are identical.

A similarity graph is the directed graph. This graph consists nodes and edges. All statements are represented by nodes, see (5), (9), and all non-zero similarities $s$ are represented by edges. The determination of a fuzzy similarity and a similarity graph is shown in the following illustrative example.

In this example, let us consider an observed variable $X$ and four statements; see Table 1 . The considered model (9) has $n=1, m=4$.

Table 1. Statements.

\begin{tabular}{cc}
\hline Statement & Variable $\boldsymbol{X}$ \\
\hline 1 & $\operatorname{High}(H)$ \\
2 & Medium $(M)$ \\
3 & Medium $(M)$ \\
4 & Small $(S)$ \\
\hline
\end{tabular}


Verbal evaluation (small, medium, high) is quantified using fuzzy sets. The fuzzy sets, see Table 2, are dictionaries for the variable $X$ in Table 1. Their graphical representation is shown in Figure 2.

Table 2. Dictionaries of the variable $X$.

\begin{tabular}{ccccc}
\hline $\boldsymbol{X}$ & $\boldsymbol{a}$ & $\boldsymbol{b}$ & $\boldsymbol{c}$ & $\boldsymbol{d}$ \\
\hline Small $(S)$ & 0 & 0 & 10 & 20 \\
Medium $(M)$ & 10 & 20 & 20 & 30 \\
High $(H)$ & 20 & 30 & 50 & 90 \\
\hline
\end{tabular}

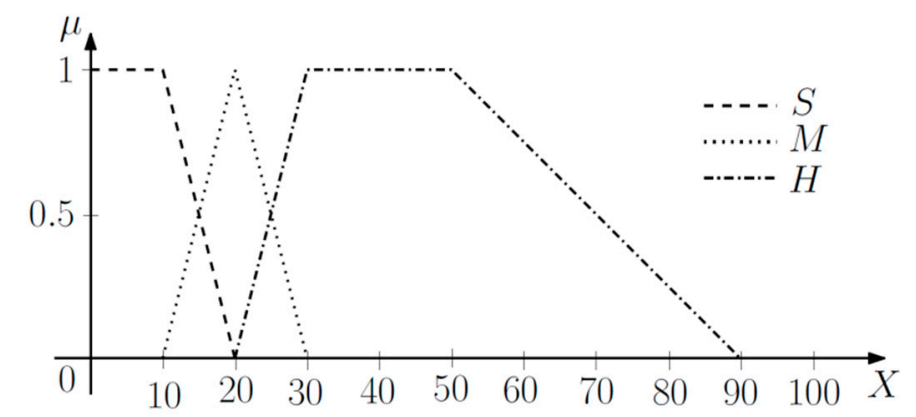

Figure 2. Grade of membership of $X$, see Table 2.

Let us consider a query $Q$ quantified using the fuzzy set (11).

$\begin{array}{llcc}a & b & c & d \\ 25 & 30 & 30 & 35\end{array}$

The graphical representation of the query $(Q)$ is shown in Figure 3.

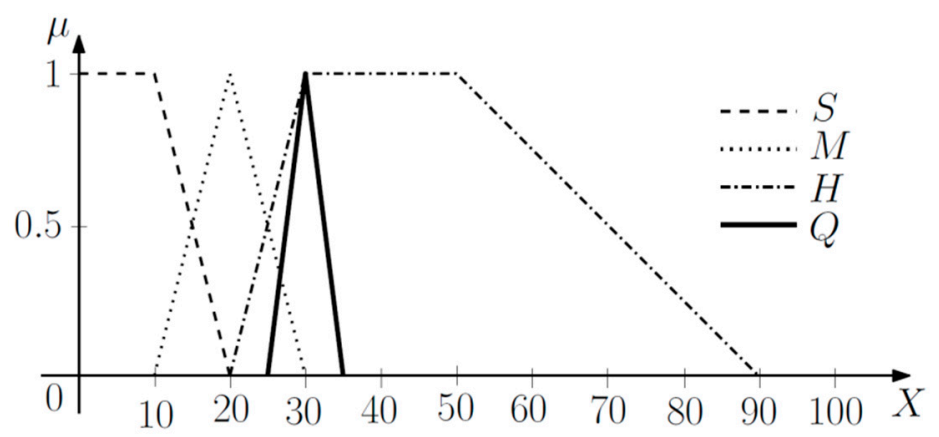

Figure 3. Grade of membership of $Q$, see (11).

The fuzzy similarities of the query $Q$ (11) with the statements, see Table 1 can be determined by (10) for $n=1$. A graphical background of the fuzzy similarity is shown in Figures 4-6.

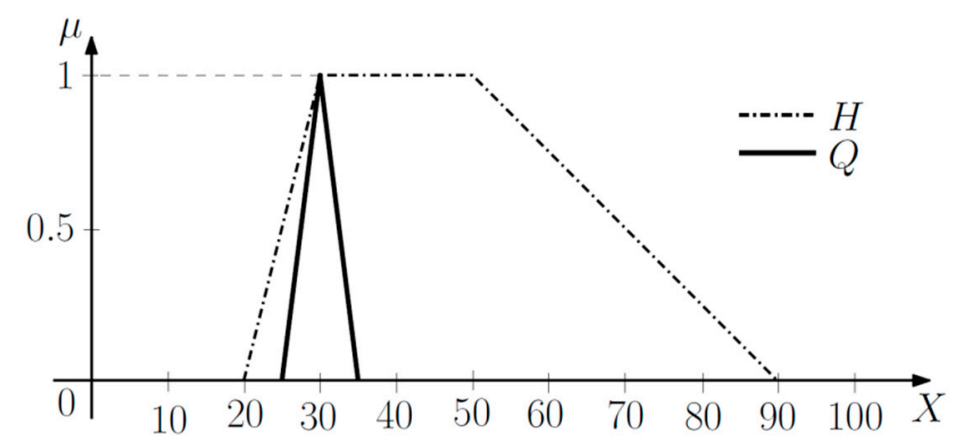

Figure 4. The fuzzy similarity between $Q$ and the first statement. 


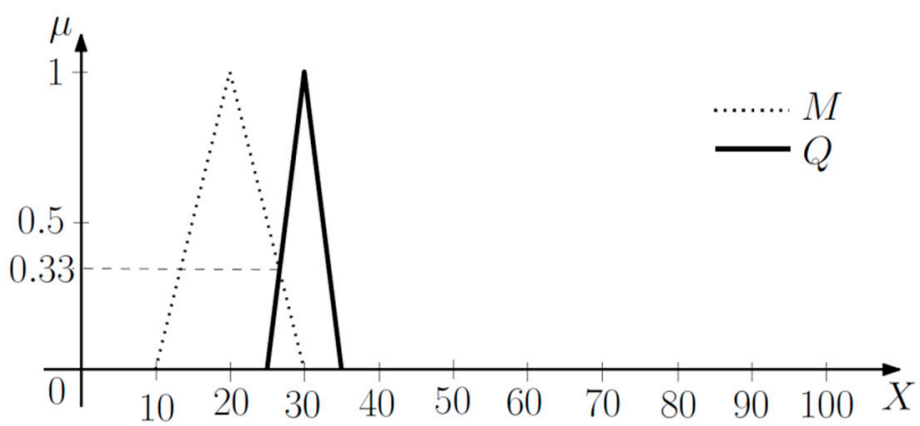

Figure 5. The fuzzy similarity between $Q$ and the second and third statement.

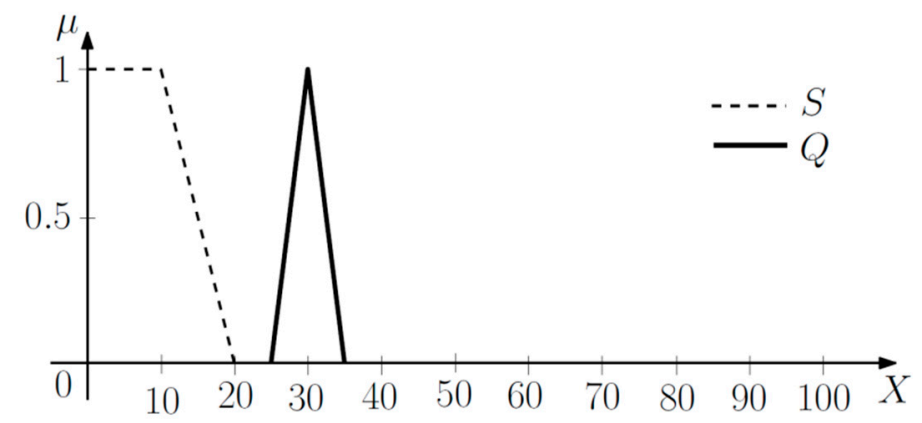

Figure 6. The fuzzy similarity between $Q$ and the fourth statement.

The numerical expression of fuzzy similarities from Figures 4-6 is seen in Table 3.

Table 3. Fuzzy similarities.

\begin{tabular}{ccc}
\hline Statement & $\boldsymbol{X}$ & Fuzzy Similarity (s), See (10) \\
\hline 1 & $\mathrm{H}$ & 1 \\
2 & $\mathrm{M}$ & 0.33 \\
3 & $\mathrm{M}$ & 0.33 \\
4 & $\mathrm{H}$ & 0 \\
\hline
\end{tabular}

The graphical representation of the result from Table 3 is shown in Figure 7.

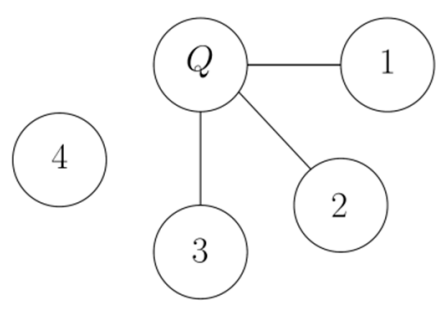

Figure 7. Similarity graph, see Table 1 and (11).

Table 3 and Figure 7 show that the first statement (the fuzzy similarity equals 1) completely suits the query. For the second and third statement, the fuzzy similarity is small. The fourth statement does not suit the query because the fuzzy similarity is zero.

In this example, only one criterion/variable was taken. It is very easy to extend this issue to several variables. Moreover, this approach may not only be used for selection, but also for comparison, e.g., finding out dependence between variables, as shown in the following case study. 


\section{Case Study}

The proposed method is applied to customers of a micro-enterprise which has three employees. This company is engaged in the production of cookies and cakes from organic ingredients and also organizes baking courses for the public. The presented case study is based on data sets of 272 respondents interviewed for research for a diploma thesis [45]. Quota selection technique was used to determine the relevant sample of respondents. Each respondent evaluated MC media. The evaluation is based on a scale $0-10$. The scale describes the media importance perceived by each respondent. Zero means that a respondent considers the communication channel completely unimportant. Zero in this case accentuates the fact that the given communication channel makes no use at all. On the contrary, a value of ten means that the given communication channel is vitally important for the respondent. Because the data set does not meet basic assumptions of parametric tests and because it is hard to say which variable is a dependent variable and which variables are independent, classical statistical methods are rejected. Therefore, respondents are sorted into five segments by age with a various number of members, see Tables 4 and 5 .

Table 4. Respondents.

\begin{tabular}{ccc}
\hline Segment & Age & Number of Respondents \\
\hline S1 & $<18$ & 14 \\
S2 & $18-28$ & 252 \\
S3 & $29-39$ & 59 \\
S4 & $40-50$ & 33 \\
S5 & $>51$ & 14 \\
\hline
\end{tabular}

Table 5. Communications media.

\begin{tabular}{cc}
\hline Variable & Media \\
\hline V1 & E-mail \\
V2 & Social networks_Facebook and Instagram \\
V3 & Web pages \\
V4 & Newspapers \\
V5 & Posters and leaflets \\
V6 & Phone calls \\
V7 & Text messages \\
V8 & Radio \\
\hline
\end{tabular}

Basic empirical characteristics (the mean, the variance) of each variable are calculated for each segment. These characteristics are used to transform the standard scale to fuzzy sets, see Figure 1 . The fuzzy sets (12), see Figure 8, are dictionaries for all variables from Table 5.

$\begin{array}{lccccc} & a & b & c & d \\ \text { Very low (VLO) } & 0 & 0 & 1 & 3 \\ \text { Low (LOW) } & 2 & 3 & 4 & 5 \\ \text { Medium (MED) } & 4 & 5 & 6 & 7 \\ \text { High (HIG) } & 6 & 7 & 8 & 9 \\ \text { Very high (VHI) } & 8 & 9 & 10 & 10\end{array}$




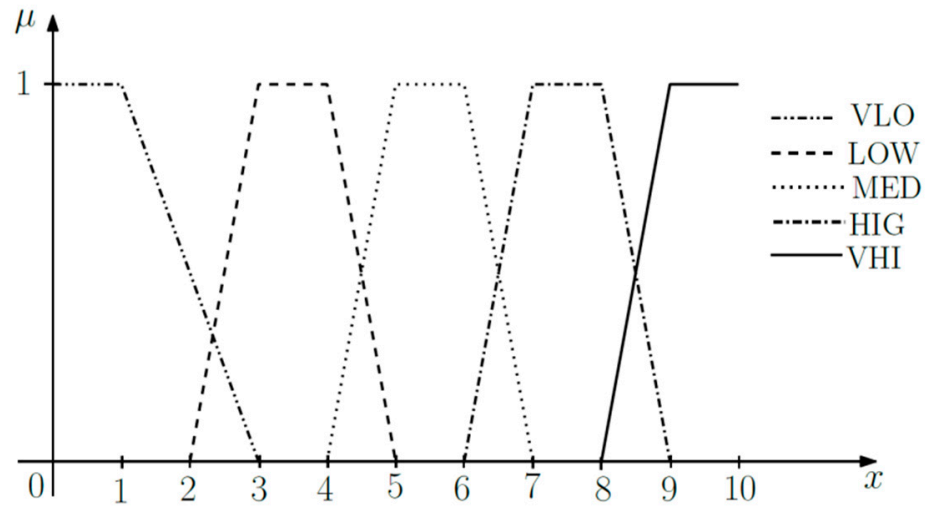

Figure 8. Fuzzy sets for each medium.

A set of five fuzzy statements was created with application of the dictionary (12), see Table 6.

Table 6. Fuzzy statements.

\begin{tabular}{ccccccccc}
\hline \multirow{2}{*}{ Segment } & \multicolumn{7}{c}{ Media } \\
\cline { 2 - 8 } & $\boldsymbol{V 1}$ & $\boldsymbol{V} \mathbf{2}$ & $\boldsymbol{V 3}$ & $\boldsymbol{V 4}$ & $\boldsymbol{V 5}$ & $\boldsymbol{V 6}$ & $\boldsymbol{V 7}$ & $\boldsymbol{V} \boldsymbol{8}$ \\
\hline S1 & LOW & MED & LOW & VLO & LOW & LOW & MED & LOW \\
S2 & MED & MED & MED & VLO & LOW & LOW & LOW & LOW \\
S3 & MED & MED & MED & VLO & LOW & VLO & LOW & VLO \\
S4 & MED & MED & LOW & VLO & LOW & LOW & LOW & VLO \\
S5 & VHI & MED & HIG & LOW & LOW & LOW & HIG & LOW \\
\hline
\end{tabular}

The intervals (12) are results of a discussion with experts. To check, they are subjected to a sensitivity analysis. The sensitivity analysis has shown that fuzzification (12) is not sensitive and therefore it has little effect on the similarity graphs below.

Three similarity graphs are studied. The first total graph (GT) focuses on all media channels, the second graph (G1) contains classical media channels, and graph G2 includes online media channels, see Table 7.

Table 7. Fuzzy similarity graphs and variables.

\begin{tabular}{cc}
\hline Fuzzy Similarity Graph & Based on Variables, See Table 5: \\
\hline GT-Total graph & all variables \\
G1-Classical & V4, V5, V6, V8 \\
G2-Online & V1, V2, V3, V7 \\
\hline
\end{tabular}

Nodes represent individual age segments of respondents. Edges show the existing similarities in the perception of individual media by these segments of respondents. Tables 8-10 give fuzzy pairwise similarities of three graphs using formulas (10).

Table 8. Fuzzy pairwise segment similarities of GT.

\begin{tabular}{ccccc}
\hline & S1 & S2 & S3 & $S 4$ \\
\hline S2 & 0.375 & & & \\
S3 & 0.265 & 0.321 & & \\
S4 & 0.296 & 0.247 & 0.298 & \\
S5 & 0 & 0 & 0 & 0 \\
\hline
\end{tabular}


Table 9. Fuzzy pairwise segments similarities of G1.

\begin{tabular}{ccccc}
\hline & $S 1$ & $S 2$ & $S 3$ & $S 4$ \\
\hline$S 2$ & 0.6 & & & \\
S3 & 0.321 & 0.265 & & \\
S4 & 0.296 & 0.247 & 0.298 & \\
S5 & 0.28 & 0.265 & 0.265 & 0.247 \\
\hline
\end{tabular}

Table 10. Fuzzy pairwise segments similarities of G2.

\begin{tabular}{lcccc}
\hline & S1 & S2 & S3 & S4 \\
\hline S2 & 0.375 & & & \\
S3 & 0.9 & 0.36 & & \\
S4 & 0.444 & 0.343 & 0.424 & \\
S5 & 0.28 & 0 & 0.365 & 0 \\
\hline
\end{tabular}

It can be seen from the GT graph (see Figure 9) that no edge leads to node 5 . If all variables (media) are taken into account, segment S5 (age: >51) differs significantly from the remaining segments of respondents. Respectively, S5 perceives the importance of individual media differently from the rest of the segments. There are edges between the other nodes. The segments S1, S2, S3, and S4 perceive the media similarly. The grade of these similarities is shown in Table 8.

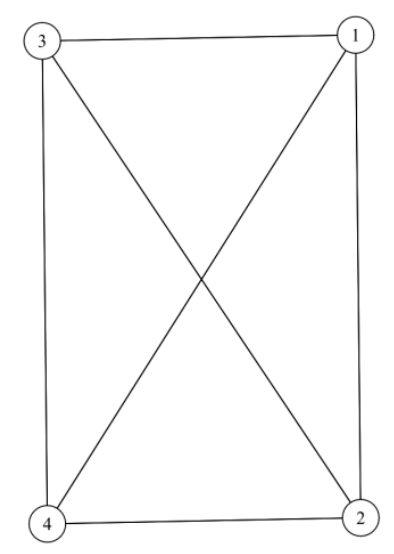

Figure 9. Fuzzy similarity total graph (GT).

Table 8 indicates that the highest grade of similarity is between segments $S 1$ and $\mathbf{S 2}$. The second highest grade of similarity is between segments $S 2$ and $S 3$. It means that there is a similar perception of media among segments of respondents that are close in age. From the results, it could be seen that marketers should approach younger respondent segments differently to older ones.

The segment $S 5$ differs from the other segments. Thus, it is important to answer the question of which media are perceived differently. For this reason, the media was divided into two groups, traditional and online.

It can be seen from graph G1 (see Figure 10) that there are edges between all nodes. There is a similarity between media perception among all segments. Grades of similarity are shown in Table 9 . The highest grade of similarity is between segments $S 1$ and $S 2$. The second highest grade of similarity is between the segments $\boldsymbol{S 1}$ and $\mathbf{S 3}$, which indicates that the same or similar marketing communication strategy could be used for these segments. 


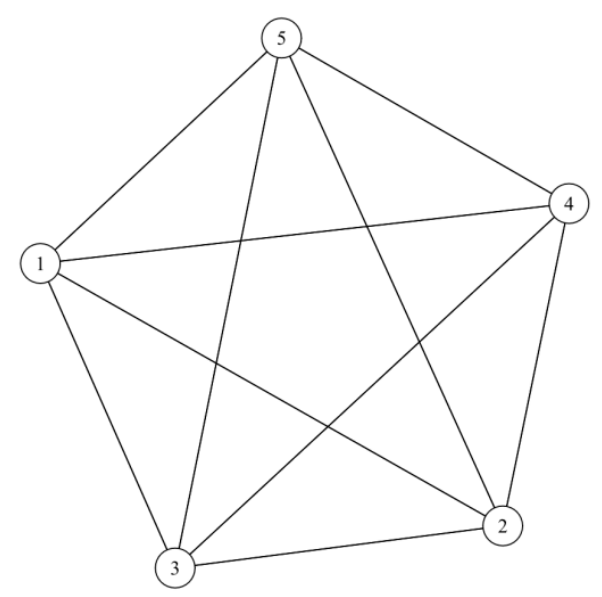

Figure 10. Fuzzy similarity classical graph (G1).

Graph G2 (see Figure 11) shows that there are edges between nodes 1, 2, 3, and 4 . There are similarities between segments $S 1, S 2, S 3$, and $S 4$. Two edges lead to node 5 . S5 is similar to $S 1$ and $S 3$. The grade of similarity is shown in Table 10. The highest grade of similarity (0.9) is between segments S1 and S3, which represents a very close perception of the media. In this case marketers can merge segments $S 1$ and $S 3$ into one compact segment and can use one marketing $S 1$ communication strategy. Interestingly, $S 5$ is similar to $S 1$, which is from the opposite age spectrum. Segment $S 5$ is also similar to $S 3$. It could be caused by the fact that children and grandchildren try to influence parents and grandparents to use online tools more.

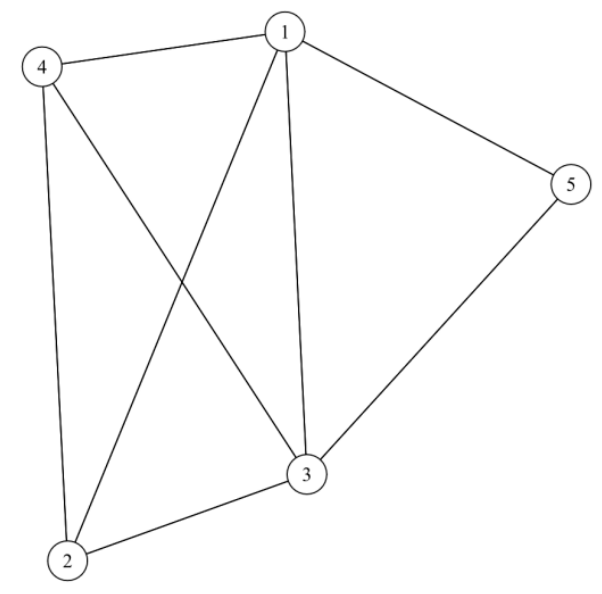

Figure 11. Fuzzy similarity online graph (G2).

\section{Discussion}

The obtained result from the case study indicates there are differences in how segments perceive marketing communication media. In the case of Table 8 and Graph GT, the perception of the media importance by the oldest age group (S5) differs from that of other age segments (S1-S4). Based on these outputs, it makes sense for the micro-enterprise to create at least two specific communication campaigns. However, based on the results of Table 9 and Graph G1, it is possible to use a similar or the same communication campaign for all aged segments if the micro-enterprise used only traditional communication media. Finally, the results of Table 10 and Graph G2 indicate that the highest grade of similarity (0.9) is between segments $S 1$ and $S 3$ and also $S 5$ is similar to $S 1$ and $S 2$. It could be caused by the fact that children and grandchildren try to influence parents and grandparents to use online tools more. 
This finding in itself is not so surprising, see [46]. However, it is interesting that the same results can be achieved with a lack of input data where finding and confirmation of a relationship using classical statistical methods is difficult.

Small entrepreneurial firms have to face the obstacle of being constrained by very limited financial resources in comparison with large enterprises, see [47]. Micro-enterprises are not able to conduct their own extensive marketing research or use the service of marketing agencies. They have difficulties getting a large enough dataset to be able to evaluate the input data appropriately. This is the crucial aspect due to the fact that micro-enterprises are the cornerstone for sustainable local economic growth. The proposed tool also allows micro-enterprises to determine an appropriate communication strategy for individual segments.

The management must bear in mind the interdisciplinary nature of most sustainability issues. Soft sciences such as sociology or a political theory must be used. The relation among the marketing communication and sustainable development is studied extensively. There is also relatively little evidence of how social aspects and the knowledge/experiences of individual traders interact. This means that the presented approach should be used for real sustainable tasks which are more complex and flexible.

Complex marketing models of interdisciplinary natures are often interrelated mixtures of verbal descriptions as well as some sub-models based on classical methods of numerical mathematics, operational research, and so on. Such (semi)subjective experiences cannot be easy to understand described by mathematical or statistical method. Conventional statistical methods, which are based on the law of large numbers, are difficult to use if the studied marketing tasks are unique and complex, see [31].

It is therefore important to identify the subjective and objective knowledge items. In order to develop the best possible model of the studied unique complex task of sustainable marketing, it is necessary to take into account knowledge items of different levels of subjectivity based on different quantifiers, such as fuzzy and rough sets, trend modeling, etc. This is the reason why information non-intensive formal tools based on verbal descriptions are increasingly being used (see, for example, naïve physics algorithms, and [48-50]).

There is an extensive body of knowledge items that have been formalized for human-readability using verbal descriptions. These verbal descriptions are difficult to model using computers which causes their little use in practical marketing tasks. Fuzzy reasoning algorithms allow computers to use verbal descriptions like human experts. However, these algorithms are far from using common sense reasoning in a way that is comparable to the human. There is a surprisingly long history of this type of research (see, e.g., [51-53]). However, the use of new approaches in artificial intelligence there is the likelihood of success in using verbal descriptions in marketing problems. This means that a marketing researcher must carefully study the development of artificial intelligence research.

\section{Conclusions}

Fewer information intensive methods of marketing analysis often achieve more realistic results in cases where the system which is being modeled is very complex. These complex tasks are usually studied at different levels of accuracy because more precise knowledge is available. As the first approach for a decision of complex tasks, market experts use experiences represented by common sense instead of mathematical models.

Fuzzy reasoning algorithms can teach computers to use verbal descriptions like human. Apart from marketing communication and green advertising, the managerial implications of the article should be seen in light of the fact that the proposed tool can be broadly used for additional fields in the sustainable marketing decision-making process by defining goal variables related to sustainable development, etc. More specifically, the tool can be used to determine: The importance of individual "green" information (recycling) within green advertising on customers; the influence of individual 
ecological measures taken by enterprises; influence of individual factors within green marketing (e.g., green labeling) on customers.

The number of observed variables has an impact on similarities. An increase of the number of variables leads to a decreasing the number of non-zero similarities. This means that similarity graphs based on a large number of variables disintegrate in (highly) separated clusters.

A potential, partial elimination of problems related to the different number of variables would be to use trends as non-numerical quantifiers, see, e.g., [54]. Trends are quantified by just three quantifiers-increasing, constant and decreasing. The trend quantifiers are the least information-intensive inputs. This is a significant advantage, because these quantifiers can be easily used to quantify personal knowledge, feelings, moods, etc. However, the most significant weakness of any trend-based marketing study is that the results will only be trend-based. It means that, e.g., a trend marketing model could be used to answer the following query: Is it possible to achieve sustainable business development by choosing appropriate marketing communication? This issue should be the scope of future research. There are also several managerial studies focused on sustainable marketing, e.g., [55-57], and in general they have not taken into account the fact that some customers care very little about an enterprise's sustainable marketing policies and marketing strategy methods [4]. In accordance with this finding, the future research perspectives should also be focused on how the proposed tool could be used to determine which sustainable marketing strategies customers really value.

Author Contributions: D.S.: Investigation, Resources, Validation, Writing-Original Draft Preparation; K.D.: Conceptualization, Methodology, Software, Formal Analysis, Writing-Original Draft Preparation.

Funding: This research was funded by the Czech Science Foundation grant number 17-23448S Modeling and Simulation of Sustainable Investment Decision-Making and grant number FP-S-18-5395 Challenges in Managing and Operating Business in Context of Current Business Environment.

Conflicts of Interest: The authors declare no conflict of interest.

\section{References}

1. Kotler, P.; Armstrong, G. Principles of Marketing, Global Edition; Pearson Education Limited: London, UK, 2016; ISBN 978-1-292-09249-2.

2. Kotler, P.; Rackham, N.; Krishnaswamy, S. Ending the war between Sales \& Marketing. Harv. Bus. Rev. 2006, 84, 68-78. [PubMed]

3. Roy, D.; Verplanken, B.; Griffin, C. Making Sense of Sustainability: Exploring the Subjective Meaning of Sustainable Consumption. Appl. Environ. Educ. Commun. 2015, 14, 187-195. [CrossRef]

4. Sun, Y.; Garrett, T.C.; Phau, I.; Zheng, B. Case-based models of customer-perceived sustainable marketing and its effect on perceived customer equity. J. Bus. Res 2018, in press. [CrossRef]

5. Cox, M.J. Sustainable Communication: A Study of Green Advertising and Audience Reception within the growing arena of Corporate Social Responsibility. Case Study: British Petroleum. Earth Environ. 2008, 3, $32-51$.

6. McDonagh, P. Towards a theory of Sustainable Communication in Risk Society: Relating issues of sustainability to marketing communications. J. Mark. Manag. 1998, 14, 591-622. [CrossRef]

7. Banerjee, A.; Halvorsen, K.E.; Eastmond-Spencer, A.; Sweitz, S.R. Sustainable Development for Whom and How? Exploring the Gaps between Popular Discourses and Ground Reality Using the Mexican Jatropha Biodiesel Case. Environ. Manag. 2017, 59, 912-923. [CrossRef] [PubMed]

8. Dobson, A. Green Political Thought; Routledge: London, UK, 2000; ISBN 978-0-415-22203-7.

9. Chang, H.; Zhang, L.; Xie, G.X. Message framing in green advertising: The effect of construal level and consumer environmental concern. Int. J. Advert. 2015, 34, 158-176. [CrossRef]

10. Rahim, M.H.A.; Zukni, R.Z.J.A.; Ahmad, F.; Lyndon, N. Green advertising and environmentally responsible consumer behavior: The level of awareness and perception of Malaysian youth. Asian Soc. Sci. 2012, 8, 46-54.

11. McDonald, S.; Oates, C.J. Sustainability: Consumer Perceptions and Marketing Strategies. Bus. Strategy Environ. 2006, 15, 157-170. [CrossRef]

12. McDonald, S.; Oates, C.J.; Alevizou, P.J.; Young, C.W.; Hwang, K. Individual strategies for sustainable consumption. J. Mark. Manag. 2012, 28, 445-468. [CrossRef] 
13. Vennesland, B. Measuring rural economic development in Norway using data envelopment analysis. For. Policy Econ. 2005, 7, 109-119. [CrossRef]

14. Thapa, A. Determinants of microenterprise performance in Nepal. Small Bus. Econ. 2015, 45, 581-594. [CrossRef]

15. Ayyagari, M.; Beck, T.; Demirguc-Kunt, A. Small and Medium Enterprises Across the Globe. Small Bus. Econ. 2007, 29, 415-434. [CrossRef]

16. European Commission. Commission Recommendation of 6 May 2003 Concerning the Definition of Micro, Small and Medium-Sized Enterprises. (Text with EEA Relevance) (Notified under Document Number C (2003) 1422), CELEX1. Available online: https://publications.europa.eu/en/publication-detail/-/publication/ 6ca8d655-126b-4a42-ada4-e9058fa45155/language-en (accessed on 10 September 2019).

17. Vargas, C. Community development and micro-enterprises: Fostering sustainable development. Sustain. Dev. 2000, 8, 11-26. [CrossRef]

18. Kardos, M.; Gabor, M.R.; Cristache, N. Green Marketing's Roles in Sustainability and Ecopreneurship. Case Study: Green Packaging's Impact on Romanian Young Consumers' Environmental Responsibility. Sustainability 2019, 11, 873. [CrossRef]

19. Smith, P.A.C.; Sharicz, C. The shift needed for sustainability. Learn. Organ. 2011, 18, 73-86. [CrossRef]

20. Hisrich, R.; Peters, M.; Shepherd, D. Entrepreneurship, 9th ed.; Department of Sociology, Stockholm University: Stockholm, Sweden, 2012; ISBN 978-0-07-749913-6.

21. Duffett, R.; Edu, T.; Haydam, N.; Negricea, I.C.; Zaharia, R. A Multi-Dimensional Approach of Green Marketing Competitive Advantage: A Perspective of Small Medium and Micro Enterprises from Western Cape, South Africa. Sustainability 2018, 10, 3764. [CrossRef]

22. Rossiter, J.R.; Danaher, P.J. Comparing perceptions of marketing communication channels. Eur. J. Mark. 2011, 45, 6-42.

23. Weber, L. Marketing to the Social Web: How Digital Customer Communities Build Your Business, 2nd ed.; John Wiley \& Sons: New York, NY, USA, 2011.

24. Wang, A. When Synergy in Marketing Communication Online Enhances Audience Response: The Effects of Varying Advertising and Product Publicity Messages. J. Advert. Res. 2006, 46, 160-170. [CrossRef]

25. Naik, P.A.; Raman, K. Understanding the Impact of Synergy in Multimedia Communications. J. Mark. Res. 2003, 40, 375-388. [CrossRef]

26. Chang, Y.; Thorson, E. Television and Web advertising synergies. J. Advert. 2013, 33, 75-84. [CrossRef]

27. Dijkstra, M.; Buijtels, H.E.J.J.M.; van Raaij, W.F. Separate and joint effects of medium type on consumer responses: A comparison of television, print, and the Internet. J. Bus. Res. 2005, 58, 377-386. [CrossRef]

28. Aznarte, J.L.; Molina, D.; Sánchez, A.M.; Benítez, J.M. A test for the homoscedasticity of the residuals in fuzzy rule-based forecasters. Appl. Intell. 2011, 34, 386-393. [CrossRef]

29. Tabachnick, B.G.; Fidell, L.S. Using Multivariate Statistics; Allyn and Bacon: Boston, MA, USA, 2001; ISBN 978-0-321-05677-1.

30. Mathews, P.G. Design of Experiments with MINITAB; ASQ Quality Press: Milwaukee, 2005; ISBN 978-0-87389-637-5.

31. Ross, S.M. Introductory Statistics; Elsevier: Amsterdam, The Netherlands, 2010; ISBN 978-0-08-092210-2.

32. Pask, F.; Lake, P.; Yang, A.; Tokos, H.; Sadhukhan, J. Sustainability indicators for industrial ovens and assessment using Fuzzy set theory and Monte Carlo simulation. J. Clean. Prod. 2017, 140, 1217-1225. [CrossRef]

33. Dočekalová, M.P.; Doubravský, K.; Dohnal, M.; Kocmanová, A. Evaluations of corporate sustainability indicators based on fuzzy similarity graphs. Ecol. Indic. 2017, 78, 108-114. [CrossRef]

34. Zadeh, L.; Polak, E. System Theory, 1st ed.; McGraw-Hill: New York, NY, USA, 1969; ISBN 978-0-07-072747-2.

35. Dohnal, M. Ignorance and uncertainty in reliability reasoning. Microelectron. Reliab. 1992, 32, 1157-1170. [CrossRef]

36. Dubois, D. On various ways of tackling incomplete information in statistics. Int. J. Approx. Reason. 2014, 55, 1570-1574. [CrossRef]

37. Dubois, D.; Fargier, H.; Perny, P. Qualitative decision theory with preference relations and comparative uncertainty: An axiomatic approach. Artif. Intell. 2003, 148, 219-260. [CrossRef]

38. Cox, E.D. Fuzzy Logic for Business and Industry; Charles River Media Inc.: Rockland, 1995; ISBN 978-1-886801-01-1. 
39. DuBois, D.B.P. Fuzzy Sets and Systems: Theory and Applications; Academic Press Inc.: Cambridge, MA, USA, 1997; ISBN 978-0-12-222750-9.

40. Liu, K.F.R.; Yu, C.W. Integrating case-based and fuzzy reasoning to qualitatively predict risk in an environmental impact assessment review. Environ. Model. Softw. 2009, 24, 1241-1251. [CrossRef]

41. Vesely, S.; Klöckner, C.A.; Dohnal, M. Predicting recycling behaviour: Comparison of a linear regression model and a fuzzy logic model. Waste Manag. 2016, 49, 530-536. [CrossRef]

42. Davidova, O.; Lacko, B. Fuzzy logic control application for the risk quantification of projects for automation. Adv. Intell. Syst. Comput. 2019, 837, 320-326.

43. Dubois, D.; Fargier, H.; Ababou, M.; Guyonnet, D. A fuzzy constraint-based approach to data reconciliation in material flow analysis. Int. J. Gen. Syst. 2014, 43, 787-809. [CrossRef]

44. Dohnal, M. A Chaos-Based Analysis of Discriminative Power of Fuzzy Models. J. Intell. Fuzzy Syst. 1996, 4 , 49-63.

45. Machová, M. Marketingová Strategie (Marketing Strategy). Master Thesis, Brno University of Technology, Brno, Czech, 2018.

46. Madhavaram, S.; Hunt, S.D. The service-dominant logic and a hierarchy of operant resources: Developing masterful operant resources and implications for marketing strategy. J. Acad. Mark. Sci. 2008, 36, 67-82. [CrossRef]

47. Chaston, I. Entrepreneurial Management in Small Firms; Sage Publications: London, UK, 2010.

48. Day, B.; Pinto Prades, J.L. Ordering anomalies in choice experiments. J. Environ. Econ. Manag. 2010, 59, 271-285. [CrossRef]

49. Dohnal, M. A methodology for common-sense model development. Comput. Ind. 1991, 16, 141-158. [CrossRef]

50. Lipmann, O.; Bogen, H. Naive Physik Theoretische und Experimentelle Untersuchungen über die Fähigkeit zu Intelligentem Handeln; Barth: Leipzig, Germany, 1923.

51. Rust, R.T. The future of marketing. Int. J. Res. Mark. 2019, in press. [CrossRef]

52. Dwivedi, Y.K.; Hughes, L.; Ismagilova, E.; Aarts, G.; Coombs, C.; Crick, T.; Duan, Y.; Dwivedi, R.; Edwards, J.; Eirug, A.; et al. Artificial Intelligence (AI): Multidisciplinary perspectives on emerging challenges, opportunities, and agenda for research, practice and policy. Int. J. Inf. Manag. 2019, in press. [CrossRef]

53. Martínez-López, F.J.; Casillas, J. Artificial intelligence-based systems applied in industrial marketing: An historical overview, current and future insights. Ind. Mark. Manag. 2013, 42, 489-495. [CrossRef]

54. Dohnal, M.; Doubravsky, K. Equationless and equation-based trend models of prohibitively complex technological and related forecasts. Technol. Forecast. Soc. Chang. 2016, 111, 297-304. [CrossRef]

55. Mariadoss, B.J.; Tansuhaj, P.S.; Mouri, N. Marketing capabilities and innovation-based strategies for environmental sustainability: An exploratory investigation of B2B firms. Ind. Mark. Manag. 2011, 40, 1305-1318. [CrossRef]

56. Charlo, M.J.; Moya, I.; Muñoz, A.M. Sustainable Development and Corporate Financial Performance: A Study Based on the FTSE4Good IBEX Index. Bus. Strategy Environ. 2015, 24, 277-288. [CrossRef]

57. Yu, Y.; Choi, Y. Corporate social responsibility and firm performance through the mediating effect of organizational trust in Chinese firms. Chin. Manag. Stud. 2014, 8, 577-592. [CrossRef]

(C) 2019 by the authors. Licensee MDPI, Basel, Switzerland. This article is an open access article distributed under the terms and conditions of the Creative Commons Attribution (CC BY) license (http://creativecommons.org/licenses/by/4.0/). 